\title{
Matrix method for X-ray stress measurement in single crystals, and the rational planning of the measurements \\ Balder Ortner
}

\author{
Schillerstrasse 34, Leoben, Austria \\ Balder.Ortner@aon.at
}

Keywords: single crystal, $\mathrm{x}$-ray stress measurement, matrix method

\begin{abstract}
With the so-called matrix method stress calculation from x-ray diffraction measurements is much easier than it used to be with older methods. The matrix method is also well suited to optimize the choice of reflections (hkl) to be measured in order to obtain the best results with least experimental effort. Pseudocodes for the stress calculation are given.
\end{abstract}

\section{Introduction}

In $[1,2]$ two methods are described for x-ray stress measurements in single crystals and single crystal films. At that time both methods have been designed in a way that it is a little bit cumbersome to implement them in a computer program. In the meantime we developed what we call matrix method or generalized $\sin ^{2} \psi$ method. This method is not only well suited for stress measurement in polycrystalline materials with or without a texture, it can also easily be applied for single crystalline specimens. One difference to the older methods is the greater elegance and simplicity. The other difference is this: in our new method we aim directly to calculate the stress tensor, whereas in the older methods we took an intermediate step by calculating at first the strain tensor and from the strain tensor the stress is calculated. We further gave recipes for the optimized choice of measurement positions (hkl). But these recipes refer to optimizing the strain tensor which does not necessarily mean to optimize the stress tensor. With the matrix method it is possible to do the selection of the (hkl)s so that one obtains maximum accuracy in $\sigma_{i j}$ with minimum experimental effort. A further difference to [1] and [2] is that these papers are written only for cubic crystal systems.

\section{Principle of the matrix method}

The matrix method is based on Eq. 1 the famous equation discovered by Dölle and Hauk $[3,4]$.

$$
\varepsilon(\varphi, \psi, \mathrm{hkl})=\mathrm{F}_{\mathrm{ij}}(\varphi, \psi, \mathrm{hkl}) \sigma_{\mathrm{ij}}
$$

This is the original form of Dölle-Hauk's equation. When applied to single crystal stress measurement one can omit $\varphi$ and $\psi$ since the measurement direction is already determined by (hkl). (But here (hkl) means always a special permutation of the Miller indices, including the correct sign.) Therefore instead of Eq. 1 we can write Eq. 2, and if we use Voigt's notation we come to Eq. 3.

$$
\begin{array}{ll}
\varepsilon(\mathrm{hkl})=\mathrm{F}_{\mathrm{ij}}(\mathrm{hkl}) \sigma_{\mathrm{ij}}, & \mathrm{i}, \mathrm{j}=1 . .3 \\
\varepsilon(\mathrm{hkl})=\mathrm{F}_{\mathrm{m}}(\mathrm{hkl}) \sigma_{\mathrm{m}} & \mathrm{m}=1 . .6
\end{array}
$$

To convert $\varepsilon_{\mathrm{ij}}$ to $\varepsilon_{\mathrm{m}}$ or $\mathrm{F}_{\mathrm{ij}}$ to $\mathrm{F}_{\mathrm{m}}$ and back one must use the schema of Eq. 4

$$
\left\{\mathrm{F}_{1}, \mathrm{~F}_{2}, \mathrm{~F}_{3}, \mathrm{~F}_{4}, \mathrm{~F}_{5}, \mathrm{~F}_{6}\right\}=\left\{\mathrm{F}_{11}, \mathrm{~F}_{22}, \mathrm{~F}_{33}, 2 \mathrm{~F}_{23}, 2 \mathrm{~F}_{13}, 2 \mathrm{~F}_{12}\right\}
$$

Eq. 3 can be used if all components of the stress tensor are unknown or at least the diagonal elements of the stress tensor are unknown. 
When the specimen has a stress free surface not only the stress but also the stress free lattice constant can be evaluated. $[1,5,6]$ In this case Eq. 6 must be used. $[5,6]$

$$
\mathrm{a}(\mathrm{hkl})=\mathrm{a}_{0}+\mathrm{F}_{11}(\mathrm{hkl}) \mathrm{a}_{0} \sigma_{11}+\mathrm{F}_{22}(\mathrm{hkl}) \mathrm{a}_{0} \sigma_{22}+2 \mathrm{~F}_{12}(\mathrm{hkl}) \mathrm{a}_{0} \sigma_{12}
$$

In the one index notation it reads

$$
\mathrm{a}(\mathrm{hkl})=\mathrm{a}_{0}+\mathrm{F}_{1}(\mathrm{hkl}) \mathrm{a}_{0} \sigma_{1}+\mathrm{F}_{2}(\mathrm{hkl}) \mathrm{a}_{0} \sigma_{2}+\mathrm{F}_{6}(\mathrm{hkl}) \mathrm{a}_{0} \sigma_{6}
$$

Another case which must be dealt with separately is if $\sigma 1=\sigma 2, \sigma 3=\ldots \sigma 6=0$

Then instead of Eq. 6 we must write:

$$
\mathrm{a}(\mathrm{hkl})=\mathrm{a}_{0}+\left[\mathrm{F}_{1}(\mathrm{hkl})+\mathrm{F}_{2}(\mathrm{hkl})\right] \mathrm{a}_{0} \sigma_{1}
$$

An important difference between stress measurement in single crystals and in a polycrystalline material is that in single crystals it is virtually always necessary to use more than one $\{\mathrm{hkl}\}$ which can be a challenge for the experimental part of the measurement. An example to prove that assertion is measurement with $\{\mathrm{h} 00\}$. In a single crystal only three measurement directions of that type would be possible and we would end up in a singular system if linear equations. This is the reason why in Eqs. 5,6,7 $\mathrm{a}_{0}$ and $\mathrm{a}(\mathrm{hkl})$ must be used and not $\mathrm{d}_{0}$ and $\mathrm{d}(\mathrm{hkl})$, the measured value.

Calculation of a(hkl). a(hkl) is a fictitious lattice constant calculated from the measured lattice plane distance $d(h k l)$. In general the relation between $a(h k l)$ and $d(h k l)$ is given by Eq. $8 a$. We multiply it by $a_{0}$ to get a/d for each (hkl), Eq. $8 b$. Then we have: $a(h k l)=d(h k l) a / d$.

$$
d^{-2}=h_{i} g^{i j} h_{j} ; \quad a / d=a_{0} \sqrt{ }\left(h_{i} g^{i j} h_{j}\right)=\left(h_{i} g^{, i j} h_{j}\right)^{0.5}
$$

$\mathrm{g}^{\mathrm{ij}}$ is the inverse matrix of $\mathrm{g}_{\mathrm{ij}}$, the metric tensor of the crystal coordinate system, and $\mathrm{g}^{\mathrm{ij}}=\mathrm{g}^{\mathrm{ij}} \mathrm{a}_{0}{ }^{2}$. The calculation of these two metric tensors is given below as pseudocodes. Here it must be pointed out that although $\mathrm{a}_{0}$ is a free parameter and is determined together with $\sigma$, the parameters $\mathrm{b} / \mathrm{a}, \mathrm{c} / \mathrm{a}, \alpha$, $\beta, \gamma$ must be known accurately. For a cubic system Eq. $8 b$ reduces to $a / d=\sqrt{ }\left(h^{2}+k^{2}+l^{2}\right)$.

Calculation of $\mathbf{F}_{\mathbf{m}}\left(\mathbf{h k l} \mathbf{)}\right.$. The $\mathrm{F}_{\mathrm{ij}}$-tensor for a given direction $r$ is calculated simply by a tensor reduction according to Eq. 9. [7]

$$
\mathrm{F}^{\mathrm{C}}{ }_{\mathrm{ij}}(r)=\mathrm{S}_{\mathrm{ijkl}} \mathrm{r}_{\mathrm{k}} \mathrm{r}_{1}
$$

The compliance tensor $\mathrm{S}$ is usually given in the Voigt's notation with two indices, therefore at first $\mathrm{S}_{\mathrm{ij}}$ must be converted to $\mathrm{S}_{\mathrm{ijk} \mathrm{k}}$. This can easily be done using the relationships below [8].

$$
\mathrm{S}_{\mathrm{iijj}}=\mathrm{S}_{\mathrm{ij}} ; \quad \mathrm{S}_{\mathrm{iikl}}=0.5 \mathrm{~S}_{\mathrm{i}, 9-\mathrm{k}-1} ; \quad \mathrm{S}_{\mathrm{ijkl}}=0.25 \mathrm{~S}_{9-\mathrm{i}-\mathrm{j}, 9-\mathrm{k}-1}
$$

$r_{i}$ means the components of the vector orthogonal to the measured lattice plane. In a cubic crystal system it is simply $r_{i}=h_{i} /|h|$. In the general case one has to transform (hkl) to (h'k'l'), that is Miller indices (although not integers) in the orthogonal and normalized crystal physical coordinate system. Then we must bring it to unit length. The result is the vector $r$ as used above. For the definition of the crystal physical system see e. g. [8]. To calculate (h'k'l') we use the matrix equation Eq. 11. Calculation of $\mathrm{E}_{\mathrm{ij}}$ is only given in the chapter "Pseudocodes".

$$
h_{i}^{\prime}=E_{i j} h_{j} ; \quad h_{i}, h^{\prime}{ }_{j} \text { means h, k, l and h', k', l' }
$$

$\mathrm{F}_{\mathrm{ij}}^{\mathrm{C}}(\mathrm{hkl})$ in Eq.9 is the F-tensor in the crystal coordinate system but what is needed is $\mathrm{F}$ in the specimen system. Therefore, it must be transformed to the specimen system. 
The orientation of the crystal can be determined by finding those lattice planes $(\mathrm{hkl})_{\mathrm{x}},(\mathrm{hkl})_{\mathrm{y}},(\mathrm{hkl})_{\mathrm{z}}$ which are orthogonal to the specimen axes. The orientation matrix $\mathrm{O}$ contains the vectors $\left(\mathrm{h}_{\mathrm{x}} \mathrm{k}_{\mathrm{x}}\right.$ $\left.l^{\prime}{ }_{\mathrm{x}}\right) / \mathrm{h}_{\mathrm{x}}{ }_{\mathrm{x}} \mid,\left(\mathrm{h}_{\mathrm{y}} \mathrm{k}_{\mathrm{y}} \mathrm{l}_{\mathrm{y}} \mathrm{y} /\left|\mathrm{h}{ }_{\mathrm{y}}\right|\right.$ and so on as first, second, third line.

With the orientation matrix $\mathrm{O}$ and Eq. 12 we can transform $\mathrm{F}^{\text {Crystal }}$ to $\mathrm{F}^{\text {Specimen }}$. The transformation from the two-indices to the one-index notation is done according to Eq. 4.

$$
\mathrm{F}^{\mathrm{S}} \mathrm{ij}_{\mathrm{j}}=\mathrm{O}_{\mathrm{ik}} \mathrm{O}_{\mathrm{jl}} \mathrm{F}_{\mathrm{kl}}^{\mathrm{C}}
$$

The system of linear equations. With all the equations above the system of linear equations can be established.

With Eq. 6:

$$
\mathrm{a}_{\mathrm{n}}(\mathrm{hkl})=\mathrm{a}_{0}+\mathrm{F}_{\mathrm{n} 1}(\mathrm{hkl}) \mathrm{a}_{0} \sigma_{1}+\mathrm{F}_{\mathrm{n} 2}(\mathrm{hkl}) \mathrm{a}_{0} \sigma_{2}+\mathrm{F}_{\mathrm{n} 6}(\mathrm{hkl}) \mathrm{a}_{0} \sigma_{6}
$$

$n$ means the number of the individual measurement. $\mathrm{n}=1 . . \mathrm{N}$

For the sake of simplicity we write:

$$
\begin{aligned}
& \mathrm{y}_{\mathrm{n}}=\mathrm{a}_{\mathrm{n}}(\mathrm{hkl})=\mathrm{k}_{\mathrm{nm}} \mathrm{x}_{\mathrm{m}} \quad \mathrm{m}=1 . .4 \\
& \left\{\mathrm{k}_{\mathrm{nm}}\right\}=\left\{1, \mathrm{~F}_{\mathrm{n} 1}(\mathrm{hkl}), \mathrm{F}_{\mathrm{n} 2}(\mathrm{hkl}), \mathrm{F}_{\mathrm{n} 6}(\mathrm{hkl})\right\} \\
& \left\{\mathrm{x}_{\mathrm{m}}\right\}=\left\{\mathrm{a}_{0}, \mathrm{a}_{0} \sigma_{1}, \mathrm{a}_{0} \sigma_{2}, \mathrm{a}_{0} \sigma_{6}\right\}
\end{aligned}
$$

From $\mathrm{x}_{\mathrm{m}}$ the wanted unknowns can be calculated.

$$
\mathrm{a}_{0} ;=\mathrm{x}_{1} ; \quad \sigma_{1}=\mathrm{x}_{2} / \mathrm{x}_{1} ; \quad \sigma_{2}=\mathrm{x}_{3} / \mathrm{x}_{1} ; \quad \sigma_{6}=\mathrm{x}_{4} / \mathrm{x}_{1}
$$

With Eq. 7:

$$
\begin{aligned}
& \mathrm{y}_{\mathrm{n}}=\mathrm{a}_{\mathrm{n}}(\mathrm{hkl})=\mathrm{k}_{\mathrm{nm}} \mathrm{x}_{\mathrm{m}} \quad \mathrm{m}=1,2 \\
& \left\{\mathrm{k}_{\mathrm{n} 1}, \mathrm{k}_{\mathrm{n} 2}\right\}=\left\{1,\left[\mathrm{~F}_{\mathrm{n} 1}(\mathrm{hkl})+\mathrm{F}_{\mathrm{n} 2}(\mathrm{hkl})\right]\right\} \\
& \left\{\mathrm{x}_{1}, \mathrm{x}_{2}\right\}=\left\{\mathrm{a}_{0}, \mathrm{a}_{0} \sigma\right\} \\
& \mathrm{a}_{0}=\mathrm{x}_{1} ; \quad \sigma_{1}=\sigma_{2}=\sigma=\mathrm{x}_{2} / \mathrm{a}_{0}
\end{aligned}
$$

With Eq. 3:

$$
\begin{aligned}
& \mathrm{y}_{\mathrm{n}}=\varepsilon_{\mathrm{n}}(\mathrm{hkl})=\mathrm{k}_{\mathrm{nm}} \mathrm{x}_{\mathrm{m}}=\mathrm{F}_{\mathrm{nm}}(\mathrm{hkl}) \sigma_{\mathrm{m}} ; \quad \mathrm{m}=1 . .6 \\
& \mathrm{k}_{\mathrm{nm}}=\mathrm{F}_{\mathrm{nm}}(\mathrm{hkl}) \\
& \sigma_{\mathrm{m}}=\mathrm{x}_{\mathrm{m}}
\end{aligned}
$$

Introduction of weights. In general, the individual measurements have different accuracies. In $\mathrm{x}$ ray or neutron measurements this is especially true, since different (hkl)s mean different Bragg's angles $(\theta)$ and $\theta$ influences the accuracy very strongly. (But $\theta$ is not necessarily the only reason for different accuracies.) Therefore, the different lines in the Eqs. 13, 18, 23 must be given different weights in the system of linear equations. This is simply done by multiplying both sides of these equations with the factor weight $\left(\mathrm{w}_{\mathrm{n}}\right)$. We then obtain instead of the above mentioned equations:

$\mathrm{y}_{\mathrm{n}}^{\prime}=\varepsilon_{\mathrm{n}}(\mathrm{hkl})=\mathrm{k}_{\mathrm{nm}}^{\prime} \mathrm{x}_{\mathrm{m}}$

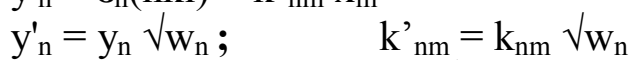

${\sqrt{\mathrm{W}_{\mathrm{n}}}}=\mathrm{f} \cdot(\Delta \mathrm{d}(\mathrm{hkl}) / \mathrm{d}(\mathrm{hkl}))^{-1} ; \mathrm{f} .$. an arbitrary factor

If the standard deviation $\Delta \mathrm{d}(\mathrm{hkl})$ is assumed to be only dependent from $\theta(\mathrm{hkl})$ we obtain

${\sqrt{\mathrm{W}_{\mathrm{n}}}}_{\mathrm{f}}=\mathrm{f} \cdot \tan (\theta(\mathrm{hkl}))$ 
But in most cases $\Delta \mathrm{d}(\mathrm{hkl})$ is not only dependent on Bragg's angle, one should also take the line width, the intensity of the reflection (counting statistics) and further influences into account.

Solution of the equations. The equations above, which have always the form $\mathrm{y}_{\mathrm{n}}=\mathrm{k}_{\mathrm{nm}} \mathrm{x}_{\mathrm{m}}$, are the basis of a system of linear equations, written as matrix equations:

$$
\mathrm{Y}^{\prime}=\mathrm{K}^{\prime} \cdot \mathrm{X}
$$

The easiest way to solve Eq. 28 would be of course to use a command for solving matrix equations in one of the programs like Mathematica, Matlab etc.

If one wants to solve the system of linear equation in an own program the single steps are:

$$
\begin{aligned}
& \mathrm{P}=\mathrm{K}^{\mathrm{6}} \cdot \mathrm{K}^{\mathrm{6}} \\
& \mathrm{Q}=\mathrm{P}^{-1} \\
& \mathrm{~K} \dagger=\mathrm{Q} \cdot \mathrm{K}^{\mathrm{6} \mathrm{T}} \\
& \mathrm{X}=\mathrm{K} \dagger \cdot \mathrm{Y}^{\prime}
\end{aligned}
$$

The matrices are:

$$
\begin{aligned}
& Y: y_{n} \\
& K^{\prime}: k^{\prime}{ }_{n m} \\
& X: x_{m}
\end{aligned}
$$

\section{The optimized choice of measurement directions}

Here we do not deal with the question of how to choose measurement direction to obtain high accuracy in $\mathrm{a}_{0}$ (Eq. 17 and Eq. 21). If $\Delta \mathrm{a}_{0}$ is to be minimized we refer to [1]. We only aim to minimize the errors in the stress tensor.

Similar to [2] we define a low quotient of a mean value of $\Delta^{2} \sigma$ to $\Delta^{2}$ a as criterion for the selection of the (hkl)s.

$$
\overline{\Delta \sigma^{2}}=\sum \Delta \sigma_{i j}^{2} / 9
$$

The same equation in the one index notation:

$$
\overline{\Delta \sigma^{2}}=\left[\Delta \sigma_{1}^{2}+\Delta \sigma_{2}^{2}+\Delta \sigma_{3}^{2}+2\left(\Delta \sigma_{4}^{2}+\Delta \sigma_{5}^{2}+\Delta \sigma_{6}^{2}\right)\right] / 9
$$

If the calculation is done according to Eq. 6 we must use Eq. 38 instead of Eq. 37

$$
\overline{\Delta \sigma^{2}}=\left[\Delta \sigma_{1}^{2}+\Delta \sigma_{2}^{2}+2 \Delta \sigma_{6}^{2}\right] / 4
$$

For the $\Delta \sigma$ we can write:

$$
\Delta \sigma_{1}^{2}=Q_{22} \Delta a^{2}, \quad \Delta \sigma_{2}^{2}=Q_{33} \Delta a^{2}, \quad \Delta \sigma_{6}^{2}=Q_{44} \Delta a^{2}
$$

Therefore we obtain $\overline{\Delta \sigma^{2}}=\left[Q_{22}+Q_{33}+2 Q_{44}\right] / 4 \Delta a^{2}=Q \Delta a^{2}$

Stress measurement according to Eq. 7:

$\overline{\Delta \sigma^{2}}=\Delta \sigma^{2}=Q_{22} \Delta a^{2}=Q \Delta a^{2}$

Stress measurement according to Eq. 3 
$\overline{\Delta \sigma^{2}}=\left[Q_{11}+Q_{22}+Q_{44}+2\left(Q_{44}+Q_{55}+Q_{66}\right)\right] / 9 \Delta a^{2}=Q \Delta a^{2}$

Obviously a good configuration of (hkl)s for measurement is one with $\mathrm{Q}$ as small as possible.

Strategy to select a good configuration of (hkl)s. The first step is to find a great number of possible reflections (hkl), say some dozens. This is not difficult since in single crystal diffraction it is possible to obtain sharp reflections even at high Miller indices. For example, if a Si single crystal is measured with MoK $\alpha\left(\mathrm{h}^{2}+\mathrm{k}^{2}+\mathrm{l}^{2}\right)$ could go up to 200, enabling a great variety of $\{\mathrm{hkl}\}$. For these (hkl)s F1 .. F6 and the weights have to be calculated. The weight will primarily depend on Bragg's angle $\left(1 / \tan ^{2} \theta\right)$. The next step is to select any set of $N(h k l) s, N$ is the number of the planned $\theta$ measurements. For that set the quantity Q is calculated. The third step is to exchange one (hkl) in that set by another (hkl) and calculate the new Q. If Q is smaller than before the new (hkl) is kept and the same procedure is repeated.

\section{Pseudocode to establish and solve the system of linear equations.}

We start at the point where the lattice plane distances are already measured and weights are calculated and the orientation of crystal relative to the specimen coordinate system is known. If there is the full tensor to be determined (Eq. 3) also $a_{0}$ must be known.

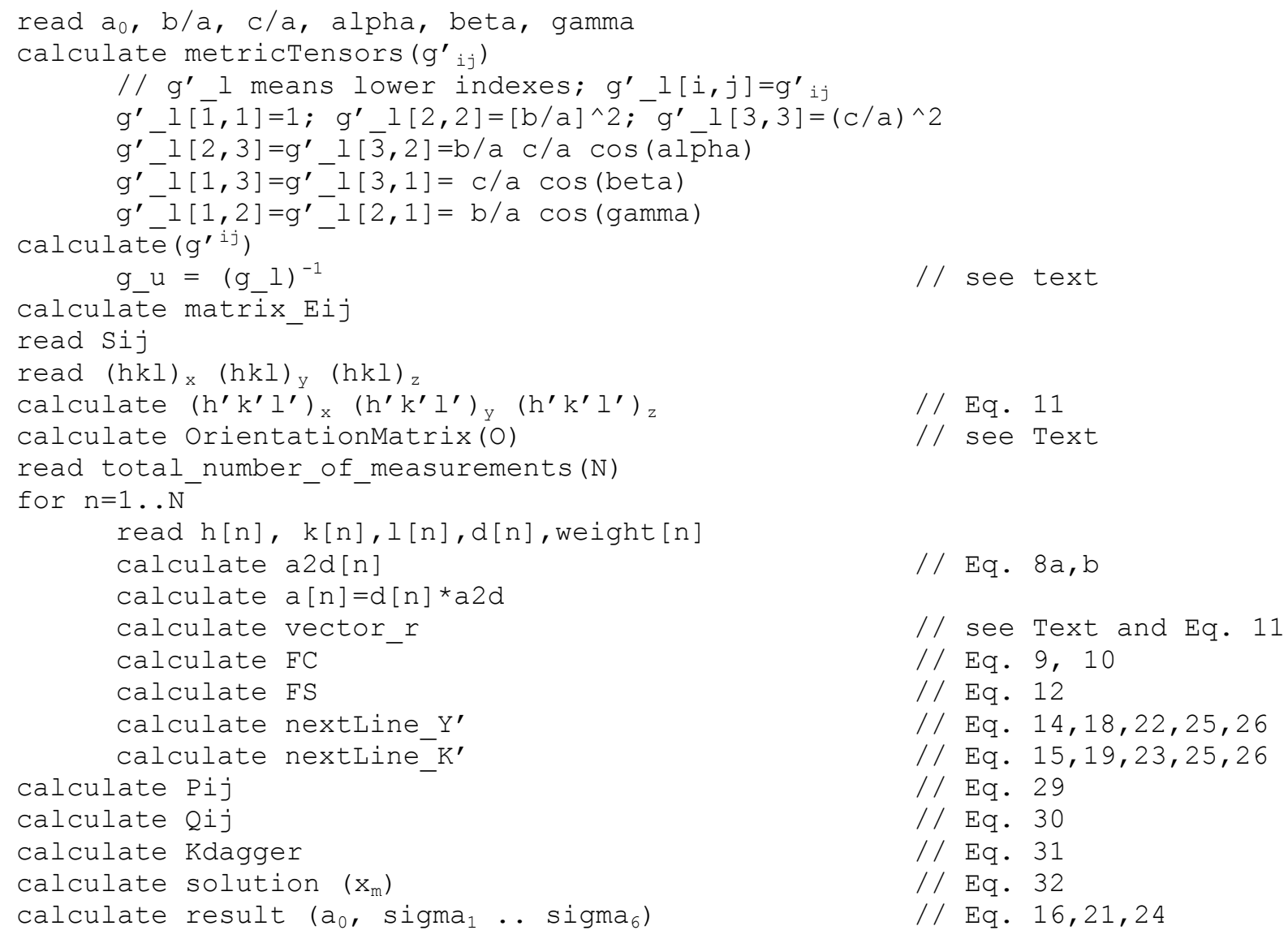

\section{Summary}

For x-ray stress determination in single crystals the matrix method is not only easier to use than older methods are, it also facilitates a correct error calculation. With the correct error calculation we have been able to develop a method (computer program) to optimize the selection of the x-ray reflections (hkl) for measurement. 


\section{References}

[1] B. Ortner, Simultaneous determination of the lattice constant and elastic strain in cubic single crystals by X-Ray diffraction, Advances in X-Ray Analysis 29(1986) 387-394, Plenum, N.Y.

[2] B. Ortner, The choice of lattice planes in X-Ray strain measurement of single crystals, Advances in X-Ray Analysis 29(1986) p.113-118, Plenum N.Y.

[3] H. Dölle, V. Hauk, Einfluß derf mechanischen Anisotropie des Vielkristalls (Textur) auf die röntgenographische Spannungsermittlung, Z. Metallkd. 69 (1979) pp 410-417

[4] H. Dölle, "The Influence of Multiaxial Stress States, Stress Gradients and Elastic

Anisotropy on the Evolution of (Residual) Stresses by X-rays", J. Appl. Cryst. 12(1979) 489-501

[5] S.J. Skrzypek, et al.,New approach to stress analysis based on grazing-incidence X-ray diffraction, J. Appl. Cryst. 34 (2001) 427-435,

[6] B. Ortner, Why we should give up the $\sin ^{2} \psi$ method, Powder Diffraction 24_2-sup (2009) S16$\mathrm{S} 21$

[7] B. Ortner, Symmetry properties and transformation behaviour of the X-ray stress factors J. Appl. Cryst. 39 (2006) 401_409

[8] S. Haussühl, Physical Properties of crystals, Wiley-VCH, Weinheim, 2007 